\title{
EDITORIAL
}

\section{Directions for future research}

Undoubtedly, all persons in this country aspire for Sri Lanka to become an economically developed nation where the people are happy and contended. If one is to consider the last five decades, the countries that have overcome poverty and became economically developed nations achieved this through the application of scientific and technological research and innovation. These nations have applied their research findings in agriculture and industry to innovate, commercialise and industrialise.

Innovations which result in new products that can be commercialised will no doubt bring wealth to the country. Innovations in agriculture, industry and service sectors will also contribute heavily to our economy. While focusing on the economy of the country, the relevant authorities must also pay close attention to the environment of the country. Sri Lanka can ill afford to destroy the beautiful environment of the country by conducting certain activities in the name of development.
As pointed out in a previous editorial, a state policy of a blue-green economy is laudable. It is now left to the researchers to work in that direction when deciding on research projects. The researchers can do this only if the state and private sector organisations that support and sponsor research ensure funding projects that will result in findings, which are of importance to the advancement of the country's economy. Decision makers of these organisations are therefore in enviable position to ensure the correct directions for research in the country. These decision makers must also keep in mind that they have to support the state policies.

It is my strong belief that decision makers of these research sponsoring organisations along with the researching scientists and technologists can contribute heavily to a happy and contended society in Sri Lanka.

Nalini Ratnasiri 